Rodolfo Cláudio SPERS ${ }^{1}$ Aleksandrs SPERS²

Wilson Roberto FERNANDES²

José Antônio VISINTIN² Rubens Paes de ARRUDA² Cledson Augusto GARCIA ${ }^{1}$

Corrspondência para: RODOLFOCLÁUDIOSPERS

Rua Palmares, 296 - Bloco-04, Apto-32 17501-510-Marília-SP

Recebido para publicação: 03/10/2005 Aprovado para publicação: 10/12/2006

\title{
Efeito da suplementação dietética com óleo de babaçu sobre o desempenho de éguas em lactação
}

\author{
1 - Faculdade de Ciências Agrárias, Curso de Pós Graduação UNIMAR, \\ Marília - SP \\ 2 - Faculdade de Medicina Veterinária e Zootecnia, USP, São Paulo - SP
}

\begin{abstract}
Resumo
A exigência nutricional das éguas é mais alta nos primeiros três meses de lactação. A energia é importante para que possam manter a condição corporal e produzir leite para os potros. Investigou-se o efeito da variação do peso corporal de éguas em lactação mantidas sob uma dieta suplementada por um concentrado com quatro níveis $(0,4,8$ e $16 \%$ ) de óleo de babaçu. Foram utilizadas 16 éguas sem raça definida e em lactação e com peso vivo médio de $441,2 \mathrm{~kg}$. O concentrado usado na suplementação dos animais foi de 1,5\% do peso vivo, sendo composto de quirera de milho, farelo de soja e farelo de trigo com 16\% de proteína bruta. A água e o volumoso constituído de Napier e suplemento mineral foram fornecidos ad libitum. As éguas foram colocadas em baias individuais $(4 \times 5 \mathrm{~m})$ onde receberam as 4 dietas, uma vez ao dia. As dietas foram oferecidas durante 42 dias. Ao término do experimento observou-se que a suplementação com óleo de babaçu não afetou condição corporal das éguas. Os resultados indicaram que, em condições tropicais, pode-se suplementar a alimentação com até 4\% de óleo de babaçu.
\end{abstract}

\section{Introdução}

À semelhança dos outros animais, o eqüino, exige na sua alimentação vários nutrientes, como, energia, carboidratos, lipídeos, proteínas e ainda minerais e vitaminas. Esses nutrientes atendem às necessidades das diferentes fases da vida animal: manutenção, crescimento, engorda, gestação, lactação e trabalho. De todas as fases citadas, a lactação é a mais exigente, pois apresenta a maior demanda de nutrientes, principalmente de energéticos. A égua, nas primeiras semanas de lactação, além dos nutrientes para a manutenção, pode requerer vários outros, considerando a possibilidade de estar em nova gestação, de ser submetida a trabalho, mesmo que moderado, e de produzir grandes quantidades de leite, cujo principal substrato energético é a lactose. Mas, para atender a toda essa exigência, deve ser nutricionalmente muito bem manejada. Isso, porém, não ocorre, pois em geral associa-se a produção de leite apenas com a produção comercial da vaca leiteira, não se levando em conta que todos os mamíferos apresentam tal capacidade. Apesar de a vaca ser especialista em produzir grande quantidade de leite por um período mais longo que outras fêmeas, a égua também, chega a produzir até $24 \mathrm{~kg}$ de leite por dia. Uma das falhas mais comuns cometidas na criação de eqüinos, tanto pelos proprietários como pelos próprios nutricionistas, é a de sub-alimentar as fêmeas durante a lactação. Torna-se, indispensável, portanto, corrigir esse descuido e atender bem suas necessidades através dos alimentos e seus nutrientes, a começar pelo provimento energético ${ }^{1}$. Afinal, evitando-se a subalimentação da égua e de seu potro desvia-se dos problemas envolvidos, como crescimento reduzido, baixa eficiência reprodutiva e predisposição as várias en

Entretanto, além da manutenção e das condições de produção da lactante e do 
potro, há outras necessidades a serem supridas através das fontes energéticas, porém, poucos estudos foram realizados a respeito das diferentes fontes de suplementação energética para éguas na fase de lactação. Shepetov, Mulikov e Gaidash. ${ }^{3}$ e Pagan, Hintz e Rounsaville. ${ }^{4}$ estudaram a suplementação com o carboidrato (amido) um nutriente energético proveniente principalmente de cereais, como o milho e a aveia. Mais escassos são os trabalhos em que a suplementação energética é feita com gordura, como na avaliação de Zimmerman ${ }^{5}$. Mas não foram detectadas diferenças nos teores de gordura e proteína, nem na quantidade de leite produzida (Santos et al. $)^{6}$. Contrariamente, Davinson et al. ${ }^{7}$, observaram que quando se aumenta a gordura na dieta obtém-se o aumento dos seus teores no leite. Diante da escassez de pesquisa sobre o tema, Doreau e Boulot ${ }^{8}$, em revisão sobre a produção de leite de éguas, confirmaram a necessidade de mais trabalhos nessa área. A literatura mais recente tem apresentado trabalhos com a suplementação de gordura, mas para animais de esporte. Assim, as gorduras vêm recebendo maior atenção quando comparadas com outros nutrientes acrescentados à alimentação animal em virtude de sua grande importância na qualidade das dietas. Elas oferecem as seguintes vantagens: aumentam a aceitabilidade das rações; proporcionam maior densidade energética; constituem fontes de ácidos graxos essenciais; são importantes na absorção das vitaminas lipossolúveis; diminuem a poeira das rações e ainda estabilizam a mistura de alimentos. Dessa forma, com a perspectiva do potencial de aproveitamento e consumo, desenvolveram-se diferentes tipos de gordura, algumas de alta qualidade e presentes no mercado a preços competitivos. Entre as gorduras naturais disponíveis, o óleo de babaçu se destaca por apresentar grande quantidade de ácidos graxos de cadeia carbônica curta e média (C8:0 e C12:0), enquanto em outras gorduras vegetais, como a da soja e amendoim, predominam os ácidos graxos de cadeia longa (C18:0 e C18:1). Os resultados obtidos com o uso de óleo de babaçu na alimentação animal não podem ser deduzidos no caso de animais de outras espécies. Aplicam-se somente a eqüino, animal herbívoro monogástrico, que dispõe de mecanismos específicos reguladores de sua ingestão e secreções digestivas (Linzel et al.) $)^{9}$.

Assim, o presente trabalho descreve os efeitos da suplementação de dietas de éguas em lactação com óleo de babaçu na variação do peso corporal, no consumo médio total e diário de concentrado, nas taxas de carboidratos solúveis, lipídeos, energia digestível e proteína bruta, e em relação ao peso metabólico desses animais em função dos níveis de suplementação.

\section{Material e Métodos}

Foram utilizadas 16 éguas em início de lactação, com potro ao pé e obtidas de gestações com sincronização dos cios, e, portanto, nascidas de partos ocorridos em períodos próximos. Eram animais sem raça definida, com peso médio de 441,2 $\mathrm{kg}$ e idade variando de quatro a oito anos. As éguas foram mantidas em pastagem de Napier, tendo acesso a água e mistura mineral ad libitum e sendo recolhidas uma vez ao dia em baias individuais (4 X $5 \mathrm{~m}$ ), para receberem a suplementação alimentar em cochos. Essa suplementação com o concentrado foi calculada em $1,5 \%$ do peso vivo em matéria seca. Toda e qualquer eventual sobra de ração foi pesada diariamente para o cálculo do consumo efetivo dos nutrientes. Para a avaliação de seus desempenhos, os animais foram pesados individualmente sempre pela manhã, antes da suplementação a cada 21 dias, sendo D-0, D-21 e D-42. Os ingredientes e sua composição química das dietas são mostrados na tabela 1. As dietas foram formuladas segundo $\mathrm{NRC}^{10}$, sua composição centesimal e seus nutrientes, como carboidratos solúveis, lipídeos e proteínas, em função dos níveis de 
Tabela 1 - Composição química dos ingredientes das dietas de lactação.

\begin{tabular}{lccccc}
\hline Ingredientes & MS & ED & EE & CHO & PB \\
\hline Quirera de milho & 87,5 & 3,41 & 3,9 & 74,5 & 8,9 \\
Farelo de soja & 90,0 & 2,98 & 1,1 & 40,8 & 45,3 \\
Farelo de trigo & 86,6 & 2,62 & 0,8 & 56,6 & 16,2 \\
Óleo de babaçu & 99,0 & 8,54 & 99,0 & - & - \\
\hline
\end{tabular}

$\mathrm{MS}=\%$ matéria seca; $\mathrm{ED}=$ energia digestível $\left(\mathrm{Mcal}_{\mathrm{kg}} \mathrm{kg}^{-1}\right) ; \mathrm{EE}=\%$ extrato etéreo; $\mathrm{CHO}=\%$ carboidratos solúveis; $\mathrm{PB}=\%$ proteína bruta

Tabela 2 - Composição centesimal e calculada da dieta de lactação e seus nutrientes, em função dos níveis 0, 4,8 e 16 (\%) de suplementação com óleo de babaçu

\begin{tabular}{lcccc}
\hline $\begin{array}{c}\text { Composição (\%) } \\
\text { Ingredientes }\end{array}$ & 0 & \multicolumn{4}{c}{ Níveis de Óleo de Babaçu } \\
\hline Quirera de milho & 55,0 & 51,0 & 47,0 & 16 \\
Farelo de soja & 20,0 & 20,0 & 20,0 & 20,0 \\
Farelo de trigo & 20,0 & 20,0 & 20,0 & 20,0 \\
Óleo de babaçu & 0,0 & 4,0 & 8,0 & 16,0 \\
Sal mineral & 1,5 & 1,5 & 1,5 & 1,5 \\
Calcário calcítico & 1,5 & 1,5 & 1,5 & 1,5 \\
Fosfato bicálcico & 1,0 & 1,0 & 1,0 & 1,0 \\
Sal comum & 1,0 & 1,0 & 1,0 & 1,0 \\
Total & 100,0 & 100,0 & 100,0 & 100,0 \\
\hline Composição & & & & \\
Calculada (1) & & & 89,28 & 93,70 \\
\multicolumn{1}{c}{ MS } & 88,34 & 88,82 & 3,40 & 3,94 \\
ED & 2,99 & 3,20 & 10,13 & 17,89 \\
EE & 2,48 & 6,32 & 54,49 & 51,51 \\
CHO & 60,38 & 57,47 & 16,52 & 16,16 \\
\hline PB & 17,24 & 16,88 & & \\
\hline
\end{tabular}

(1) Valores calculados com base no NRC. Nutrient requirements of horses, (1989).

$\mathrm{MS}=\%$ matéria seca; $\mathrm{ED}=$ energia digestível $\left(\mathrm{Mcal} . \mathrm{kg}^{-1}\right) ; \mathrm{EE}=\%$ extrato etéreo; $\mathrm{CHO}=\%$ carboidratos solúveis; $\mathrm{PB}=\%$ proteína bruta

suplementação, constam da tabela 2. Foram estudadas as relações nutritivas e o consumo médio total e diário de concentrado, de carboidratos solúveis, lipídeos, energia digestível e proteína bruta, nos períodos mencionados e em relação ao peso metabólico $\left(\mathrm{PEM}^{0,75}\right)$ das éguas em função das porcentagens de suplementação com óleo de babaçu. Em virtude da nãoutilização de aditivos (antioxidantes), para controlar os problemas de oxidação de rações com grandes quantidades de gordura, tomou-se o cuidado de confeccionar as dietas semanalmente e acondicioná-las em local coberto, arejado e à temperatura ambiente.

\section{Delineamento experimental:}

$\mathrm{O}$ delineamento experimental foi o de blocos ao acaso com quatro tratamentos ( $0,4,8$ e $16 \%$ de óleo de babaçu) e quatro repetições. Os resultados foram submetidos à análise de variância e regressão, e as médias dos tratamentos, comparadas pelo teste de Tukey $(\mathrm{P}<0,05)\left(\right.$ Steel e Torrie) ${ }^{11}$. Utilizouse o PROC GLM do SAS ${ }^{12}$, sendo adotado 
o seguinte modelo matemático:

$\mathrm{Y}_{\mathrm{ijk}}=\mathrm{m}+\mathrm{OB}_{\mathrm{i}}+\mathrm{B}_{\mathrm{i}}+\mathrm{e}_{\mathrm{ijk}}$

$\mathrm{Y}_{\mathrm{ij \textrm {j }}}^{\mathrm{ijk}}=$ observação individual

$\mathrm{m}=$ média geral;

$\mathrm{OB}^{\mathrm{i}}=$ efeito do i ésimo nível de óleo

de babaçu ( $i=1,2,3$ e 4$)$; $2,3$ e 4$)$

$\mathrm{B}_{\mathrm{j}}=$ efeito do $\mathrm{j}$ ésimo bloco $(\mathrm{j}=1$,

$\mathrm{e}_{\mathrm{ij \textrm {k }}}=$ erro experimental

\section{Resultados e Discussão}

O peso das éguas e as suas variações diárias, durante os períodos estudados, constam na tabela 3 . Não se verificaram, pela análise de variância, diferenças significativas entre os tratamentos nos diferentes períodos (D-0, D-21 e D-42). Os coeficientes de variação foram baixos, no máximo de $8,30 \%$, ao contrário da variação de peso, em que os coeficientes de variação foram altos: de 54,8 a 335,9\%. Essa grande variação ocorreu em virtude da observância simultânea de ganhos e perdas durante o período experimental, como verificado no tratamento 4-OB. Quanto aos demais tratamentos as éguas revelaram ganho de peso total e diário de $0,476 \mathrm{~kg}$ no período inicial, enquanto no tratamento $0-\mathrm{OB}$ houve perda de $-0,629 \mathrm{~kg}$, a maior de todas.

A tendência de perda de peso das éguas se deu à medida que avançava a lactação, de $-0,267$ para $-0,533 \mathrm{~kg}$. Os resultados da análise de regressão encontramse na tabela 4, e a respectiva equação das regressões quadrática e linear, na figura 1. Não foi observado efeito significativo em razão dos níveis de suplementação com óleo de babaçu.

Desses resultados pode-se verificar que a suplementação foi mais eficiente para a menor perda de peso das éguas com o tratamento $4-\mathrm{OB}(-0,179 \mathrm{~kg})$ do que com os tratamentos $0-\mathrm{OB}(-0,471 \mathrm{~kg}), 8-\mathrm{OB}(-$ $0,460 \mathrm{~kg})$ e $16-\mathrm{OB}(-0,495 \mathrm{~kg})$, durante todo o período experimental. Esses resultados concordam com as afirmações de Doureau et al. ${ }^{13}$, segundo os quais para atender as exigências de éguas, no início da lactação e manter sua condição corporal nessa fase é necessária a suplementação com concentrados ricos em energia.

Como afirmaram Rosset, Doreau e Espinasse ${ }^{14}$, o resultado obtido em ganho e

Tabela 3 - Peso, variação do peso e peso metabólico das éguas (PE) com 0 dia, com 21 dias e com 42 dias, em função das porcentagens de suplementação com óleo de babaçu

\begin{tabular}{cccccccc}
\hline Variáveis & $0-\mathrm{OB}$ & $4-\mathrm{OB}$ & $8-\mathrm{OB}$ & $16-\mathrm{OB}$ & $\mathrm{X}$ & $\mathrm{CV}$ & $(\mathrm{P}>\mathrm{F})$ \\
\hline Peso das Éguas (PE) (kg) & & & & & & & \\
D-0 & 410,8 & 442,0 & 452,0 & 460,3 & 441,3 & 7,42 & 0,22 \\
D-21 & 397,5 & 452,0 & 440,5 & 452,5 & 435,6 & 7,90 & 0,15 \\
D-42 & 391,0 & 434,5 & 432,8 & 439,5 & 424,4 & 8,30 & 0,25 \\
X & 399,7 & 438,6 & 441,7 & 450,7 & 432,7 & 7,71 & 0,21 \\
PEM 0,75 $^{0.79,4}$ & 96,5 & 96,4 & 97,8 & 95,1 & 6,13 & 0,24 \\
Variação do PE, (kg) & & & & & & & \\
D21-D0 & $-13,2$ & $+10,0$ & $-11,5$ & $-7,8$ & $-5,6$ & 335,9 & 0,34 \\
D42-D21 & $-6,6$ & $-17,5$ & $-7,8$ & $-13,0$ & $-11,2$ & 130,7 & 0,70 \\
D42-D0 & $-19,8$ & $-7,5$ & $-19,3$ & $-20,8$ & $-16,8$ & 54,8 & 0,21 \\
Variação diária do PE(kg d $\left.{ }^{-1}\right)$ & & & & & & & \\
D21-D0 & $-0,629$ & $+0,476$ & $-0,548$ & $-0,371$ & $-0,267$ & 335,9 & 0,34 \\
D42-D21 & $-0,314$ & $-0,833$ & $-0,371$ & $-0,619$ & $-0,533$ & 130,7 & 0,70 \\
D42-D0 & $-0,471$ & $-0,179$ & $-0,460$ & $-0,495$ & $-0,400$ & 54,8 & 0,21 \\
\hline
\end{tabular}

$\mathrm{X}=$ média dos níveis de óleo de bababçu; $\mathrm{CV}=$ coeficiente de variação; $(\mathrm{P}>\mathrm{F})$ = probabilidade de significância do teste $\mathrm{F}$ 
Tabela 4 - Análise de regressão do peso e do peso metabólico das éguas em função das porcentagens de suplementação com óleo de babaçu

\begin{tabular}{lccccccc}
\hline Variáveis & Equação & $\mathrm{R}^{2}$ & $\operatorname{Pr}>\mathrm{F}$ & $\mathrm{CV}$ & $\mathrm{EPGL}$ & $\mathrm{EPGQ}$ & EPI \\
\hline Peso das Éguas, $(\mathrm{kg})$ & & & & & & & \\
PE & $\mathrm{Y}=400+16,5 \mathrm{X}-\mathrm{X}^{2}$ & 0,06 & 0,27 & 20,00 & 36,17 & 6,80 & 43,3 \\
PEM $^{0,75}$ & $\mathrm{Y}=89,4+3,2 \mathrm{X}$ & 0,07 & 0,31 & 14,48 & 5,75 & 1,08 & 6,88 \\
\hline
\end{tabular}

$\mathrm{R}^{2}=$ coeficiente de determinação; $\mathrm{Pr}>\mathrm{F}=$ probabilidade $\%$ de significância do teste $\mathrm{F} ; \mathrm{CV}=$ coeficiente de variação; $\mathrm{EPGL}=$ erro padrão do gradiente linear;EPGQ = erro padrão do gradiente quadrático; $\mathrm{EPI}=$ erro padrão do intercepto

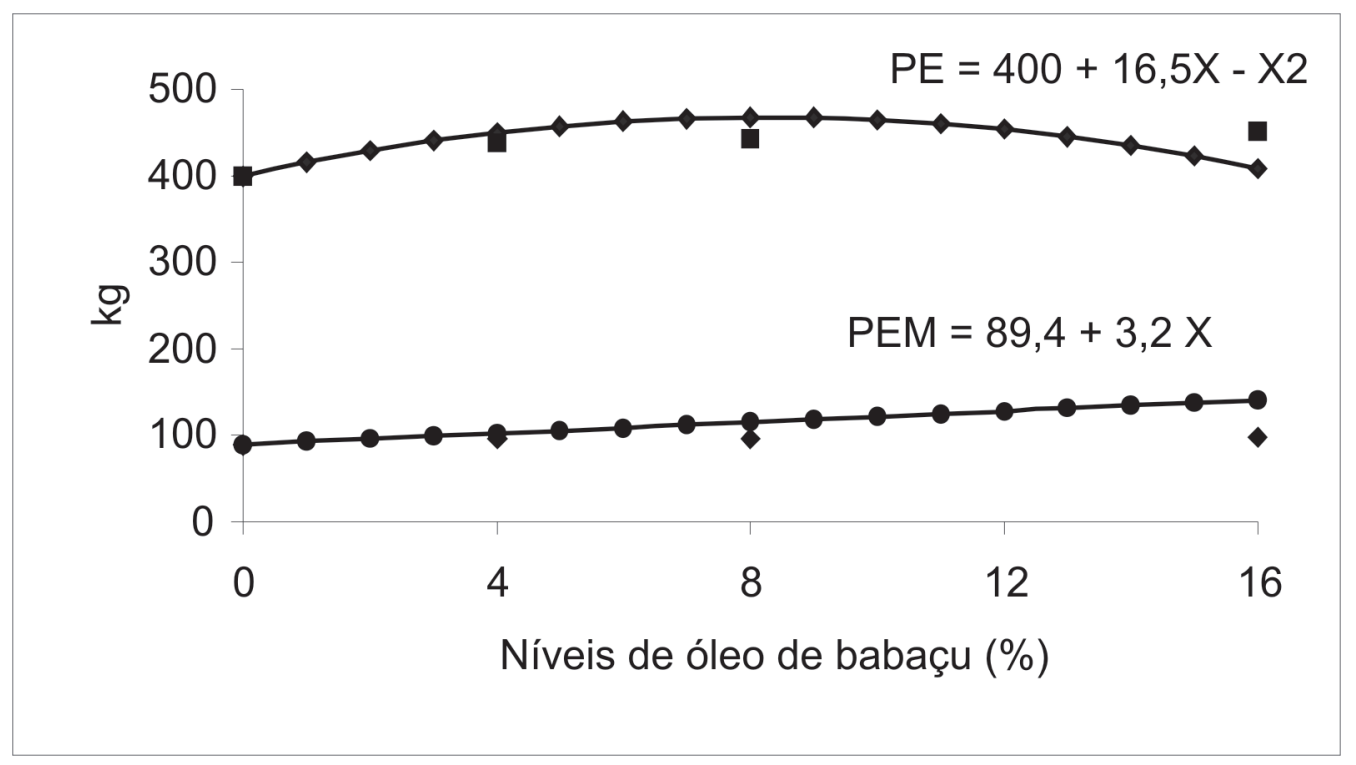

Figura 1 - Equação de regressão do peso (PE) e do peso metabólico $\left(\mathrm{PEM}^{0,75}\right)$ das éguas em função das porcentagens de suplementação com óleo de babaçu

perda de peso no tratamento 4-OB, pode ser atribuído provavelmente, a várias causas, como a variação do conteúdo digestivo, o tamanho do potro ao nascer, o potencial de produção de leite, o escore corporal etc. Contrariamente a esses dados, Doreau et al. ${ }^{15}$ observaram, no início da lactação, somente ganho de peso das éguas. Deve-se ressaltar que todas essas variações, dependem do período experimental, da condição corporal das éguas e principalmente da quantidade e qualidade das pastagens, e da suplementação fornecida (Pinto, Oliveira e Seno) ${ }^{16}$.

O peso médio das éguas também foi transformado em peso metabólico (Tabela 3). Nem a análise de variância nem a de regressão (Tabela 4), revelaram efeitos significativos. Assim, vale afirmar que o peso metabólico das éguas seguiu a mesma tendência do peso médio. A respectiva equação de regressão consta na figura 1 .

Foi avaliado o consumo de concentrado total e diário, além do peso médio e peso metabólico (Tabela 5). Quanto ao consumo de concentrado, verificaramse, através da análise de variância, diferenças significativas tanto no consumo total $(\mathrm{P}<$ $0,005)$ como no diário $(\mathrm{P}<0,004)$. No consumo total, os tratamentos 0,4 e $8-\mathrm{OB}$ foram semelhantes. $O$ menor consumo ocorreu no tratamento $16-\mathrm{OB}$, tendo sido diferente do consumo observado nos tratamentos 0 e 4-OB pelo teste Tukey. Embora tenha ocorrido redução do consumo com o aumento dos níveis de óleo de babaçu na dieta, quando se submeteram os resultados à análise de regressão (Tabela 6), não houve resultado significativo. $\mathrm{O}$ 
Tabela 5 - Consumo médio total (T) e diário (D) de concentrado, carboidratos solúveis, lipídeos, energia digestível (ED) e proteína bruta (PB), e em relação ao peso metabólico (PEM0,75) das éguas em função das porcentagens de suplementação com óleo de babaçu

\begin{tabular}{|c|c|c|c|c|c|c|c|}
\hline Variáveis & $0-\mathrm{OB}$ & $4-\mathrm{OB}$ & $8-\mathrm{OB}$ & $16-\mathrm{OB}$ & $x$ & CV & $(\mathrm{P}>\mathrm{F})$ \\
\hline \multicolumn{8}{|l|}{ Concentrado (kg) } \\
\hline $\mathrm{T}$ & $272,2^{\mathrm{a}}$ & $278,8^{\mathrm{a}}$ & $234,8^{\mathrm{ab}}$ & $190,3^{b}$ & 244,0 & 8,65 & 0,005 \\
\hline $\mathrm{D}$ & $6,50^{\mathrm{a}}$ & $6,65^{\mathrm{a}}$ & $5,59^{\mathrm{ab}}$ & $4,53^{b}$ & 5,82 & 11,17 & 0,004 \\
\hline \multicolumn{8}{|l|}{ Concentrado (g) } \\
\hline kg PE. dia ${ }^{-1}$ & $16,11^{\mathrm{a}}$ & $15,17^{b}$ & $12,68^{c}$ & $10,01^{d}$ & 13,49 & 2,72 & 0,0001 \\
\hline $\mathrm{kg} \mathrm{PEM}^{0,75} \cdot \mathrm{dia}^{-1}$ & $71,75^{\mathrm{a}}$ & $69,25^{\mathrm{a}}$ & $58,03^{b}$ & $46,10^{c}$ & 61,28 & 5,15 & 0,0001 \\
\hline \multicolumn{8}{|l|}{ Carboidratos solúveis (g) } \\
\hline kg PEM ${ }^{0,75} \cdot \mathrm{dia}^{-1}$ & $43,33^{\mathrm{a}}$ & $39,81^{\mathrm{a}}$ & $31,61^{b}$ & $23,74^{\mathrm{C}}$ & 34,62 & 5,68 & 0,0001 \\
\hline \multicolumn{8}{|l|}{ Lipídeos (g) } \\
\hline kg PEM ${ }^{0,75} \cdot$ dia $^{-1}$ & $1,78^{d}$ & $4,38^{c}$ & $5,88^{b}$ & $8,36^{\mathrm{a}}$ & 5,10 & 3,46 & 0,0001 \\
\hline \multicolumn{8}{|l|}{ ED (Mcal.kg-1) } \\
\hline $\mathrm{T}$ & 813,9 & 892,2 & 798,4 & 749,8 & 813,6 & 9,50 & 0,14 \\
\hline $\mathrm{D}$ & 19,4 & 21,3 & 19,0 & 17,8 & 19,4 & 9,33 & 0,13 \\
\hline PEM $^{0,75}$ & $0,21^{\mathrm{ab}}$ & $0,22^{\mathrm{a}}$ & $0,19^{b c}$ & $0,18^{c}$ & 0,20 & 4,51 & 0,0003 \\
\hline \multicolumn{8}{|l|}{ Proteína bruta (g) } \\
\hline $\mathrm{dia}^{-1}$ & $1120,6^{a}$ & $1122,5^{\mathrm{a}}$ & $925,1^{\mathrm{ab}}$ & $713,3^{b}$ & 974,9 & 11,70 & 0,003 \\
\hline kg PEM ${ }^{0,75} \cdot \mathrm{dia}^{-1}$ & $12,73^{\mathrm{a}}$ & $11,61^{b}$ & $9,58^{\mathrm{c}}$ & $7,48^{\mathrm{d}}$ & 10,35 & 3,04 & 0,001 \\
\hline
\end{tabular}

$\mathrm{X}$ = média dos níveis de óleo de babaçu; $\mathrm{CV}=$ coeficiente de variação; $(\mathrm{P}>\mathrm{F})$ = probabilidade $(\%)$ de significância do teste $\mathrm{F}$.

$\mathrm{a}, \mathrm{b}, \mathrm{ce} \mathrm{d}=$ médias com letras diferentes diferem estatisticamente pelo teste de Tukey $(\mathrm{P}<0,05)$

Tabela 6- Análise de regressão do consumo médio total (T) e diário (D) de concentrado, carboidratos solúveis, lipídeos, energia digestível e proteína bruta em relação ou não ao peso metabólico (PE0,75) das éguas em função dos percentuais de suplementação com óleo de babaçu

\begin{tabular}{|c|c|c|c|c|c|c|c|}
\hline Variáveis & Equação & $\mathrm{R}^{2}$ & $\operatorname{Pr}>F$ & CV & EPGL & EPGQ & EPI \\
\hline \multicolumn{8}{|l|}{ Concentrado (kg) } \\
\hline $\mathrm{T}$ & $Y=272,2+12,04 X-3,11 X^{2}$ & 0,35 & 0,14 & 22,55 & 23,01 & 4,33 & 27,52 \\
\hline \multicolumn{8}{|l|}{ Concentrado (g) } \\
\hline Kg PE.dia ${ }^{-1}$ & $Y=16,11+0,10 X-0,10 X^{2}$ & 0,98 & 0,001 & 3,06 & 0,17 & 0,03 & 0,21 \\
\hline Kg PE ${ }^{0,75} \cdot$ dia $^{-1}$ & $Y=71,75+1,23 X-0,56 X^{2}$ & 0,85 & 0,001 & 8,02 & 2,06 & 0,39 & 2,46 \\
\hline \multicolumn{8}{|l|}{$\begin{array}{l}\text { Carboidratos Solúveis } \\
\text { (g) }\end{array}$} \\
\hline $\mathrm{Kg} \mathrm{PE}^{0,75} \cdot \mathrm{dia}^{-1}$ & $\mathrm{Y}=43,33-1,17 \mathrm{X}$ & 0,90 & 0,001 & 8,39 & 1,21 & 0,23 & 1,45 \\
\hline \multicolumn{8}{|l|}{ Lipídeos (g) } \\
\hline $\mathrm{Kg} P E{ }^{0,75} \cdot \mathrm{dia}^{-1}$ & $Y=1,78+0,54 X$ & 0,99 & 0,001 & 6,28 & 0,13 & 0,03 & 0,16 \\
\hline \multicolumn{8}{|l|}{ ED (Mcal.kg.dia ${ }^{-1}$ ) } \\
\hline $\mathrm{T}$ & $Y=813,9+54,7 X-10,5 X^{2}$ & 0,10 & 0,72 & 21,61 & 73,50 & 13,84 & 87,91 \\
\hline $\mathrm{PE}^{0,75}$ & $Y=0,215+0,0009 X$ & 0,66 & 0,004 & 7,14 & 0,006 & 0,001 & 0,007 \\
\hline Proteína bruta (g.dia ${ }^{-1}$ & $\begin{array}{l}Y=1.120,6+42,0 X- \\
12,5 X^{2}\end{array}$ & 0,41 & 0,08 & 22,89 & 93,3 & 17,6 & 111,6 \\
\hline
\end{tabular}

$\mathrm{R}^{2}=$ coeficiente de determinação; $\operatorname{Pr}>\mathrm{F}=$ probabilidade $(\%)$ de significância do teste $\mathrm{F} ; \mathrm{V}=$ coeficiente de variação; $\mathrm{EPGL}=$ erro padrão do gradiente linear;EPGQ = erro padrão do gradiente quadrático; $\mathrm{EPI}=$ erro padrão do intercepto 


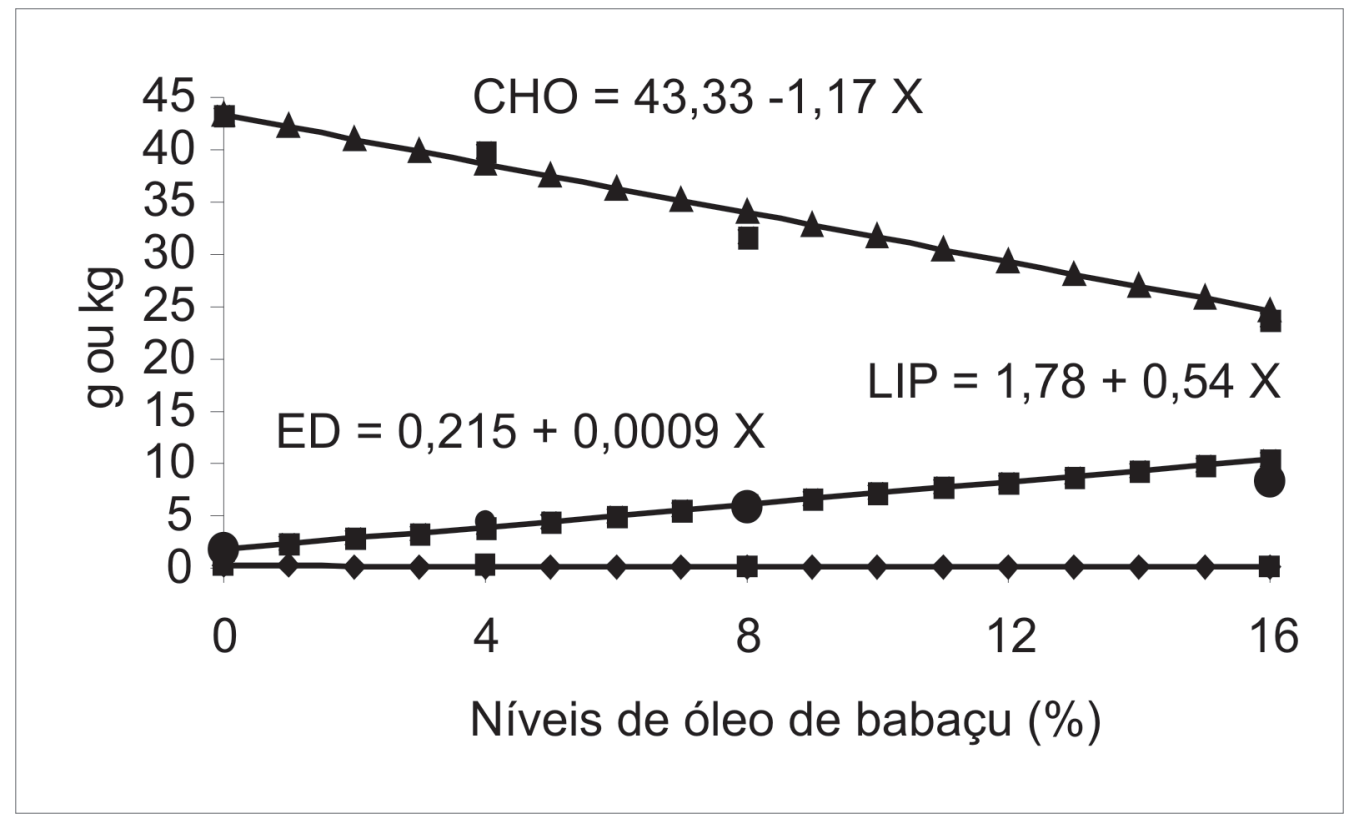

Figura 2 - Equações de regressão do consumo de carboidratos solúveis (CHO), lipídeos (LIP) e energia digestível (ED), em função do peso metabólico $\left(\mathrm{PEM}^{0,75}\right)$ das éguas segundo os percentuais de suplementação com óleo de babaçu

consumo de concentrado nas diferentes dietas em função do peso médio e peso metabólico das éguas foram diferentes pela análise de variância $(\mathrm{P}<0,0001)$, com diferenças significativas entre todos os tratamentos (Tabela 5). Como era de se esperar o consumo diário, em função do peso médio e peso metabólico também diminuiu $(\mathrm{P}<0,001)$ à medida que aumentou a suplementação com óleo de babaçu. Esses resultados foram confirmados quando submetidos à análise de regressão quadrática (Tabela 6), com efeitos significativos $(\mathrm{P}<$ $0,001)$. O coeficiente de variação foi baixo, $3,06 \%$. O aumento da inclusão de óleo de babaçu revelou efeito quadrático da suplementação, como se vê nas equações da tabela 6. A diminuição do consumo total de concentrado em função dos níveis crescentes de óleo de babaçu pode ser atribuída ao consumo individual de certos nutrientes, principalmente da gordura. Avaliou-se também o consumo de carboidratos solúveis das dietas em função do peso metabólico das éguas e observou-se efeito significativo $(\mathrm{P}<0,0001)$ e sua análise de variância (Tabela 5). Pelo teste de Tukey, os tratamentos com inclusão $0-\mathrm{OB}$ e $4-\mathrm{OB}$ foram semelhantes entre si e superiores $(\mathrm{P}<$ $0,05)$ das duas maiores inclusões, $8-\mathrm{OB}$ e $16-$ $\mathrm{OB}$, que foram diferentes entre si $(\mathrm{P}<0,05)$. Esses dados, quando submetidos à análise de regressão revelaram efeito linear significativo $(\mathrm{P}<0,001)$ (Tabela 6$)$. A equação de regressão demonstrou igualmente efeito linear para os níveis de óleo de babaçu (Figura 2).No tocante a redução do consumo de carboidratos solúveis em função do peso e do peso metabólico, essa se deveu basicamente a dois fatores: à menor concentração percentual nas dietas, e à diminuição do consumo voluntário, ambas em razão dos níveis de inclusão de óleo de babaçu.

Também foi analisado o consumo de lipídeos em função do peso metabólico das éguas, e sua análise de variância teve efeito significativo $(\mathrm{P}<0,0001)$. Esse consumo aumentou em decorrência dos níveis de suplementação com óleo de babaçu, sendo todas as médias diferentes pelo teste de Tukey (Tabela 5). A significância $(\mathrm{P}<0,001)$ foi confirmada pela análise de regressão (Tabela 6), cuja equação revelou efeito linear 
para os níveis de inclusão de óleo de babaçu (Figura 2). Esse aumento do consumo de lipídeos ocorreu devido à maior concentração percentual do óleo incluído nas dietas, e persistiu mesmo com a diminuição do consumo voluntário de concentrado pelas éguas. Cabe aqui destacar a influência dos nutrientes no consumo voluntário, principalmente da gordura. Segundo alguns autores, eles interagem com receptores do intestino delgado determinando os chamados alimentos terminais. Assim o aumento da oferta de gordura e sua acomodação no intestino delgado conferem ao animal um típico comportamento de saciedade pós prandial ${ }^{17,18}$. Essa saciedade pode persistir, segundo pesquisadores, em virtude da quantidade, do tempo de permanência no lúmen intestinal e do tipo de gordura fornecida.

Os consumos de energia digestível total e diária constam na tabela 5. A análise de variância assim como a de regressão (Tabela 6) não revelaram efeito significativo nos níveis de suplementação. Todavia, ao se considerar esse consumo em função do peso metabólico, tal efeito foi constatado $(\mathrm{P}<$ 0,0003). O maior consumo foi observado no tratamento 4-OB, tendo sido diferente do encontrado para 8 e 16-OB, porém semelhante ao 0-OB (Tabela 6). A respectiva análise de regressão revelou efeito significativo $(\mathrm{P}<0,004)$ e linear (Tabela 6$)$. A equação de regressão correspondente consta na figura 2 . O maior consumo de energia em função do peso metabólico no tratamento 4-OB, deveuse não apenas à inclusão do óleo de babaçu, mas também ao não comprometimento do consumo voluntário da dieta nesse nível de suplementação. Quantidades diferentes de gordura, porém equivalentes no teor de energia, apresentam diferentes efeitos sobre o consumo diário de alimentos, refletindo no desempenho dos animais ${ }^{18}$. O nível de suplementação 4-OB atingiu um consumo diário de energia de 21,3 Mcal valor próximo ao sugerido pelo $\mathrm{NRC}^{10}$, segundo o qual as éguas com peso corporal de $400 \mathrm{~kg}$ a $500 \mathrm{~kg}$ devem consumir de 22,9 a 28,3 Mcal, ficando o pastejo para a complementação desse consumo energético.

O consumo diário de proteína revelou efeito significativo $(\mathrm{P}<0,003)$ (Tabela 5). Pelo teste de Tukey, observou-se a mesma tendência para o consumo de concentrado, em virtude das dietas serem isoprotéicas. Foram semelhantes entre si os resultados obtidos com os três menores níveis de substituição, todavia nos níveis 0 e 4-OB eles foram estatisticamente melhores que os conseguidos no 16-OB. Ao se considerar o consumo de proteína em função do peso metabólico, o efeito foi mais significativo ( $\mathrm{P}$ $<0,001)$. Tal consumo diminuiu à medida que aumentou a suplementação com óleo de babaçu, e apresentou diferenças significativas em todos os valores observados (Tabela 5). A análise de regressão do consumo diário de proteína revelou efeito próximo da significância $(\mathrm{P}<0,08)$ (Tabela 6$)$. A diminuição do consumo de proteína diário, e em função do peso metabólico, mesmo na presença das dietas praticamente isoprotéicas, é atribuída a redução do consumo total de concentrado em decorrência da ingestão de lipídeos.

\section{Conclusões}

A suplementação da dieta das éguas em lactação com óleo de babaçu não afetou o peso das éguas e as suas variações nos diferentes períodos. O maior nível de suplementação reduziu o consumo total e diário de concentrado.

Aumentando-se suplementação houve redução do consumo de concentrado, carboidratos e proteínas em função do peso e peso metabólico das éguas; em contrapartida, o consumo de lipídeos aumentou. No tocante ao consumo de energia total e diário pelas éguas, esse não foi afetado com o aumento da suplementação. Porém em função do peso metabólico houve diminuição desse consumo nos dois maiores níveis de suplementação. 


\title{
Effect of dietary supplementation with coco-nut babaçu oil on performance of lactating mares
}

\begin{abstract}
Mares have the highest nutrient requirement in the first three months of lactation. Energy is important for mares to maintain body condition and produce milk for their foals. The effect on body weight changes were investigated through supplemental coconut oil (CO) at four levels $(0,4,8$ and $16 \%)$ in concentrate fed to 16 multiparous mares in early lactation with average body weight $441.2 \mathrm{Kg}$. Mares were fed $1,5 \%$ live weight with concentrate composed of corn meal, wheat bran and soybean meal with $16 \%$ crude protein. The forage was Napier grass, mineral supplement and water "ad libitum". Mares were allotted to 16 pens $(4 \times 5 \mathrm{~m})$ and randomly assigned to receive four diets once a day during 42 days. At the end of the experiment the $\mathrm{CO}$ supplementation did not affect mares body condition The results indicated that in tropical conditions level at 4\% CO supplementation had better results for lactating mares.
\end{abstract}

\section{Referências}

1 CUNHA, T. J. Horse feeding and nutrition. New York: Academic Press, 1991. p. 216-234.

2 MARTIN, R. G.; MCMENIAM, N. P.; DOWSET, K. F. Milk and water intakes of foal sucking grazing mares. Equine Veterinary Journal, v. 24, n. 4, p. 295-299, 1992.

3 SHEPETOV, F. N.; MULIKOV, A. I.; GAIDASH, V. A. Breeding Dairy horses around Stalingrad. Konevodstvo Konnyi Sport., v. 6, p. 41-45, 1953.

4 PAGAN, J. D.; HINTZ, H. F.; ROUNSAVILLE, T. R. The digestible energy requirements of lactating pony mares. Journal of Animal Science, v. 58, n. 6, p. 13821387, 1984.

5 ZIMMERMAN, R. A. EQ. Nutritions Physiol. Symp. 9., 1985, Michigan. Proceedings... [S. I.: s. n.], 1985 p. 96-102.Effect of ration on composition of mare's milk.

6 SANTOS, et al. Lactação em éguas da raça Mangalarga Marchador: Produção e composição do leite e ganho de peso de potros lactentes. Revista Brasileira de Zootecnia, v. 34, n. 2, p. 627-634, 2005.

7 DAVISON, K. E. et al. Lactation and reproductive performance of mares fed added dietary fat during late gestation and early lactation. Journal of Equine Veterinary Science, v. 11 n. 2, p. 111-115, 1991.

8 DOREAU, M.; BOULOT, S. Recent knowledge on milk maré production: A Review. Livestock Production Science, v. 22, p. 213-235, 1989.

9 LINZELL, J. L. et al. Mammary and whole-body metabolism of glucose, acetate and palmitate in the lactating horse. Proc. Nutr. Soc., v. 31, p. 72-73, 1972.
10 NRC. Nutrient requirements of horses. 5ed. Washington D. C.: N.R.C., 1989. p. 100.

11 STEEL, R. G. D.; TORRIE, J. H. Principles and Procedures of statistics, $2^{\text {nd }}$ ed. New York: MacgrawHill, 1980. p. 173-177.

12 SAS. User's guide: statistics version 5. Cary, NC: SAS Institute, 1985.

13 DOREAU, M. et al. Can mares be fed on small quantities of concentrates after foaling? Journee de la Recherche Chevaline, n. 14e, p. 103-114, 1988.

14 ROSSET, M.; DOREAU, M.; ESPINASSE, J. Feeding of the suckling mare: Variation in mare liveweight and growth of foals. Annales de Zootechnie., v. 35, n. 1, p. 21-36, 1986

15 DOREAU, M. et al. Yield and composition of milk from lactating mares : effect of lactating stage and individual differences. Journal of Dairy Research, $v$. 57, n. 4, p. 449-454, 1990.

16 PINTO, C. M. D.; OLIVEIRA, K.; SENO, L. O. Avaliação do desempenho de éguas a pasto em diferentes estágios de lactação. In: REUNIÃO ANUAL DA SOCIEDADE BRASILEIRA DE ZOOTECNIA, 2001, Piracicaba. Anais... [S. I.: s. n.], 2001.

17 ANTIN, J. et al. Cholecistokinin elicits the complete behavioral sequence of satiety in rats. J. Comp. Physiol. Psychol., v. 89, p. 784-790, 1975.

18 FREEMAN, B. B.; SCHNEEMAN, B. O. Lipid infused into the duodenum of rats at varied rates influences food intake and body weight gain. American Institute of Nutrition, p. 2934-2939, 1996. 